\title{
PENCEGAHAN ANEMIA PADA REMAJA PUTRI DI PONDOK PESANTREN DARUSSALAM AL-HAFIDZ KOTA JAMBI
}

\author{
Nurbaiti \\ Program Studi D III kebidanan STIKes Baiturrahim Jambi \\ Email:nbaiti812@gmail.com
}

\begin{abstract}
Nutritional anemia is a lack of hemoglobin levels in the blood caused by a lack of nutrients needed for the formation of $\mathrm{Hb}$. If a woman who has anemia will be very difficult when she is pregnant and giving birth. This can cause babies born with low weight (less than 2500 grams). In addition, anemia can also result in the death of both the mother and baby during labor. Anemia is one of the health problems throughout the world, especially developing countries. It is estimated that 30\% of the world's population suffer from anemia. The anemia in young women is still quite high. This community service activity will be held at Jambi Jambi Al-Hafidz Pondok Islamic Boarding School. The service method uses survey, lecture, discussion, demonstration / simulation approaches. Problems faced by partners Lack of student knowledge about anemia in adolescents and how to prevent it
\end{abstract}

Keywords: Nutritional; Anemia; Adolescence

\begin{abstract}
ABSTRAK
Anemia Gizi adalah kekurangan kadar hemoglobin dalam darah yang disebabkan karena kekurangan zat gizi yang diperlukan untuk pembentukan Hb.Dampak buruk bagi anemia sangat berpengaruh terhadap kesehatan reproduksi terutama pada wanita. Jika wanita mengalami anemia maka akan menjadi sangat berbahaya pada waktu dia hamil dan melahirkan. Hal tersebut bisa menyebabkan bayi lahir dengan berat badan rendah (kurang dari 2500 gram). Di samping itu, anemia juga dapat mengakibatkan kematian baik ibu maupun bayi pada waktu proses persalinan.Anemia merupakan salah satu masalah kesehatan di seluruh dunia terutama Negara berkembang yang diperkirakan $30 \%$ penduduk dunia menderita anemia.Anemia pada remaja putri sampai saat ini masih cukup tinggi. Kegiatan Pengabdian masyarakat ini akan dilaksanakan di Pondok Pesanren Darussalam Al-Hafidz Kota Jambi Metode pengabdian menggunakan pendekatan survei, ceramah, diskusi, demonstrasi/simulasi. Permasalah yang dihadapi mitra Kurangnya Pengetahuan siswa tentang anemia pada remaja dan cara pencegahannnya.
\end{abstract}

Kata Kunci: Gizi; Anemia; Remaja

\section{PENDAHULUAN}

Masa remaja merupakan masa peralihan dari masa anak-anak ke masa dewasa, yang meliputi semua perkembangan yang dialami sebagai persiapan memasuki masa dewasa dan masa yang penting dalam perjalanan kehidupan manusia. Golongan umur ini penting karena menjadi jembatan antara masa kanak-kanak yang bebas menuju masa dewasa yang menuntut tanggung jawab. (Kusmiran, 2012). 
Salah satu masalah kesehatan pada remaja yaitu anemia yang merupakan masalah gizi yang perlu mendapat perhatian khusus. Upaya yang dilakukan oleh pemerintah untuk mengatasi masalah tersebut telah menunjukkan kecukupan gizi didapatkan dari kesesuaian antara (jumlah dan jenis) makanan yang dikonsumsi, dengan kebutuhan fungsi tubuh sehingga bermanfaat bagi terpeliharanya fungsi tubuh secara optimal.(Sibagarian,2010).

Anemia merupakan salah satu masalah kesehatan di seluruh dunia terutama Negara berkembang yang diperkirakan $30 \%$ penduduk dunia menderita anemia. Anemia banyak terjadi pada remaja dan ibu hamil. Anemia pada remaja putri sampai saat ini masih cukup tinggi, menurut .World Health Organization (WHO 2013), prevelensi anemia dunia berkisar 40-88 \%. Jumlah usia remaja (10-19 tahun) di Indonesia sebanyak $26,2 \%$ yaitu terdiri dari $50,9 \%$ laki-laki dan 49,1\% perempuan (Choiriya,2015).

Menurut data hasil Reskesdas tahun 2013, prevalensi anemia di Indonesia yaitu $21,7 \%$ dengan penderita anemia berumur 5-14 tahun sebesar $26,4 \%$ dan $18,4 \%$ penderita berumur 15 24 tahun (Kemenkes RI,2014). Data Survei Kesehatan Rumah Tangga (SKRT) tahun 2012 menyatakan bahwa prevalensi anemia pada balita sebesar $40,5 \%$, ibu hamil sebesar $50,5 \%$, ibu nifas sebesar $45,1 \%$, remaja putri usia 10-18 tahun sebesar $57,1 \%$ dan usia $19-45$ tahun sebesar $39,5 \%$. Wanita mempunyai resiko terkena anemia paling tinggi terutama pada remaja putri. (Choiriya,2015)

Anemia Gizi adalah kekurangan kadar hemoglobin dalam darah yang disebabkan karena kekurangan zat gizi yang diperlukan untuk pembentukan $\mathrm{Hb}$ tersebut. Remaja putri adalah masa peralihan dari anak menjadi dewasa, ditandai dengan perubahan fisik dan mental. Perubahan fisik ditandai dengan berfungsinya alat reproduksi seperti menstruasi (umur 10-19 th). Wanita usia subur adalah wanita pada masa atau perode dimana dapat mengalami proses reproduksi. Ditandai masih mengalami menstruasi (umur 15-45 th) (Dinkes Indragiri hulu, 2016).

Remaja putri sering menderita anemia karena masa remaja masa pertumbuhan yang sangat membutuhkan zat gizi lebih tinggi.Selain itu remaja juga mengalami menstruasi setiap bulan dan kurangnya asupan zat besi pada makanan yang dikonsumsi setiap hari.sementara jumlah makanan yang dimakan lebih sedikit dari pada laki-laki karena factor ingin langsing (mody image) dan juga kebiasaan makan yang salah seperti mengkonsumsi jajanan ataupun makan kecil sebagaipenganti makanan pokok.

Faktor lain yang dapat menyebabkan anemia adalah asupan zat gisi yang tidak adekuat yaitu kebiasaan mengkonsumsi makanan yang dapat mengganggu penyerapan zat besi seperti teh atau kopi yang bersamaan waktu makan, dan kurangnya pengetahuan tentang anemia, sikap yang tidak mendukung, pendidikan ibu maupun tingkat sosial ekonomi keluaraga. Menuurut Amalia (2015) mengatakan peran petugas kesehatan juga mempengaruhi

Dampak dari anemia pada remaja putri antara lain, meurunkan daya tahan tubuh sehingga mudah terkena penyakit, menurunkanya aktivitas dan prestasi belajar di samping itu remaja yang mengalami anemia kebugaran juga menurun, sehingga menhambat prestasi olahraga dan produksivitasnya, selain itu masa remaja merupakan masa pertumbuhan yang sangat cepat, kekurangan zat besi pada masa ini merupakan tidak tercapainya tinggi badan yang optimal. Selain itu anemia yang terjadi pada remaja putri merupakan resiko terjadinya gangguan fungsi tubuh dan mental, sehingga dapat terjadi gangguan pada saat persalinan, bayi lahir dengan berat badan kurang dari 2500 gram (BBLR) (Proverawati,2011)

Pondok Pesantren Darusalam Al Hafidz merupakan tempat pendidikan agama di Kota Jambi dimana remja putrinya masih banyak yang tidak mengetahui tentang anemia. Tujuan kegiatan pengabdian masyarakat ini untuk Meningkatkan pengetahuan dan motivasi remaja putri tentang anemia agar remaja putri dapat menlakukan pencegahan terjadinya anemia..

\section{TARGET DAN LUARAN}

1. Target

Kegiatan pengabdian kepada masyarakat ini memiliki : 
a. Remaja putri yang menempuh pendidikan di Pondok Pesantren Al Hafidz Darussalam Kota Jmabi

b. Guru wali kelas

c. Remaja putri mengerti, memhami dan mampu menerapkan cara pencegahan anemia

2. Luaran

Adapun luaran dari kegiatan pengabdian ini selain pablikasi pada jurnal ilmiah dan penerapan melakukan pencegahan anemia pada dirinya sendiri dan dapat menginformasikan pada teman sekitarnya

\section{METODE PELAKSANAAN}

Kegiatan pengabdian ini dilaksanakan pada bulan November 2018 sampai Februari 2019 di Pondok Pesantren Darussalam Al-Hafidz Kota Jambi, sasaran dalam kegiatan ini adalah remaja putri yang menempuh pendidikan di Pondok Pesantren Al Hafidz Darussalam Kota Jmabi dengan metode ceramah, diskusi dan Tanya jawab, media yang di gunakan leaflead, leptop, dan infokus Tahapan kegiatan pengabdian pada masyarakat

1. Pertemuan dengan kepala sekolah dan wali kelas

2. Hsil diskusi tim pengabdian menyampaikan solusi yang akan dilaksanakan selama pengabdian

3. Melakukan penyuluhan kesehatan tentang anemia dan pencegahannya

4. Melakukan Tanya jawab

5. Pemberian media, KIE (Komunikasi Informasi dan Edukasi) Leafleat

6. Evaluasi

\section{HASIL DAN PEMBAHASAN}

Hasil kegiatan pengabdian masyarakat yang dilakukan di pondok pesantren AL Hafidz Darussalam Kota Jambi semua remaja putri mengerti tentang pengertian anemia, penyebab terjadinya anemia, tanda gejala anemia, pencegahan anemia dan penanganan jika terjadi anemia pada remaja putri serta bersedia memberikan informasi kepada teman-teman yang ada di lingkungannya.
Anemia adalah kekurangan kadar hemoglobin dalam darah yang disebabkan karena kekurangan zat gizi yang diperlukan untuk pembentukan $\mathrm{Hb}$, penyebab terjadinya anemia yaitu kurangnya mnegkonsumsii makanan yang mengandung zat besi, kehilangan darah yang berlebihan. Tanda gejala anemia yaitu mudah lelah, lemah, sering pusing, dan sering mengantuk, jika terjadi anemia dapat mengakibatkan gangguan perkembangan otak, pertumbuhan dan daya tahan tubuh menurun sehingga mudah terkena penyakit. Agar tidak terjadi nemia maka harus di lakukan pencegahan sebagai berikut :

1. Meningkatkan konsumsi makanan yang mengandung zat besi yang bersumber hewani seperti daging, ikan, ayam, hati telur dan yang bersumber dari nabati sayur dan buahbuahan

2. Fortifikasi bahan pangan yang bisa dikonsumsi dengan zat besi (gandum, roti)

3. Suplemen tablet Fe

4. Menghindari makanan yang dapat mengaggu penyerapan zat besi

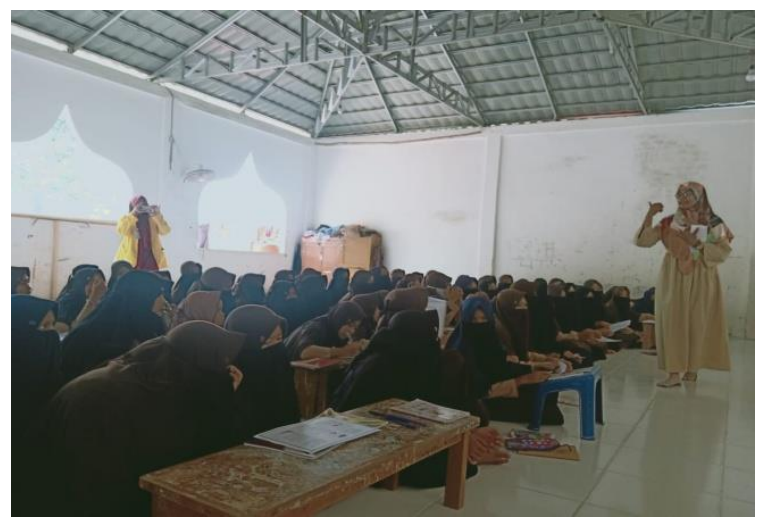

Gambar 1. Pemberian penyuluhan pencegahan anemia 


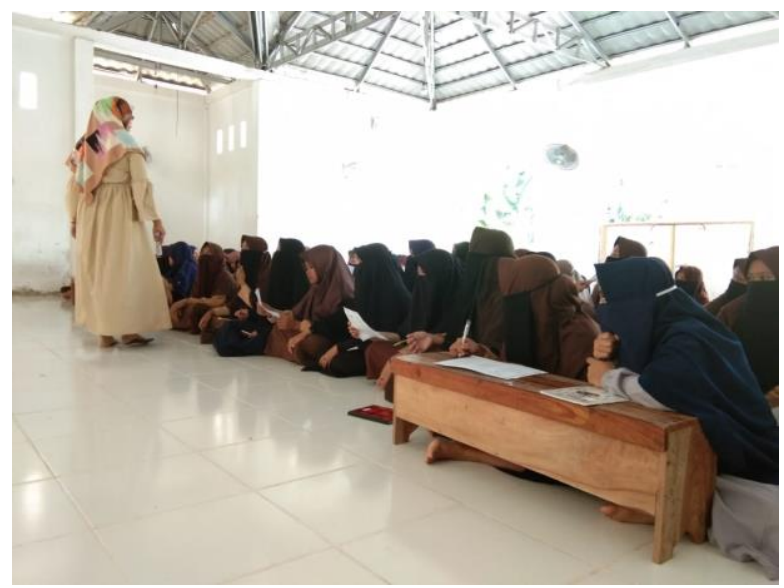

Gambar 2. Tahap akhir evaluasi

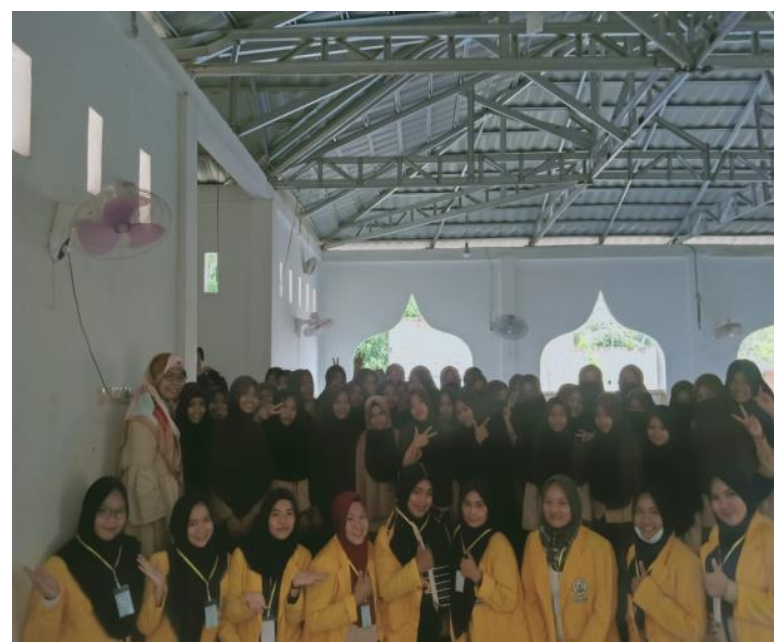

Gambar 3. Foto bersama setelah melakukan kegiatan pengabdin masyarakat

\section{KESIMPULAN DAN SARAN}

\section{Kesimpulan}

Pengabdian masyarakat dilakukan untuk Meningkatan Pengetahuan dan Motivasi remaja putri di Pondok Pesantren Darussalam Al-Hafidz Kota Jambi tentang pencegahan anemia pada remaja Putri agar remaja putri dapat melakukan pencegahan terjadinya anemia.

\section{Saran}

a. Saran agar dapat melakukan kegiatan pengabdian masyarakat secara rutin agar remaja putri mengerti tentang anemia dan melakukan pencegahan agar tidak terjadi anemia

b. Mengajukan kepada institusi pendidikan perguruan tinggi agar dapat mengatur jadwal kegiatan pengabdian masyarakat dengan mengajak mahasiswa dalam kegiatan penyuluhan

\section{UCAPAN TERIMA KASIH}

Tim pengabdian masyarakat mengucapkan terimaksih yang sebesar-besarnya kepada STIKes Baiturrahm Jambi atas dana dan fasilitas serta surat izin dalam melakukan pengabdian masyarakat ini dan juga kepada Kepala Sekolah Pondok Pesantren Darussalam AL-Hafizd serta ustadz dan ustadjah yang telah memberikan izin tempat untuk melakukan pengabdian masyarakat ini sehingga kegiatan ini berjalan dengan lancar.

\section{DAFTAR PUSTAKA}

Kusmiran, Eny. 2012. Kesehatan Reproduksi Remaja Dan Wanita. Jakarta : Selemba Medika.

Sibagariang. 2010. Kesehatan Reproduksi Wanita. Jakarta : Trans Info Media.

Dinkes Indragirihulu. 2016.http://dinkes.inhukab.go.id/puskesm aslirik/2016/08/12/.Tablet Tambah Darah Pada Siswi Smp Dan Sma Pada Pemberian Remaja Putri. 2016

Proverawati, Asfuah, 2010. Ilmu Gizi Untuk Keperawatan Dan Gizi Kesehatan.Nuha Medika : Yogyakarta

Widyastuti, Dkk. 2009. Kesehatan Reproduksi, Yogyakarta : Fitramaya 